\title{
Depression contributing to dyslipidemic cardiovascular risk in the metabolic syndrome
}

\author{
A. V. Lemche ${ }^{1}$ - O.S. Chaban ${ }^{2}$ E. Lemche ${ }^{3}$ (1)
}

Received: 7 October 2016 / Accepted: 11 December 2016 / Published online: 23 December 2016

(C) The Author(s) 2016. This article is published with open access at Springerlink.com

\begin{abstract}
Purpose Triglycerides are considered an emerging risk factor for cardiovascular mortality. Recent evidence relating depression and metabolic syndrome (MetS) implicated triglyceride levels. We thus investigated interrelations of self-reported depression severity (Zung) and MetS-related biological measures with CVD risk estimates in MetS patients.

Methods $N=101$ patients fulfilling International Diabetes Federation criteria for MetS from a nationwide sampled treatment cohort for MetS with familial T2DM risk or manifest T2DM in a Ukrainian governmental health care system were participants. Both laboratory and non-laboratory measures were included. Recent European cardiological SCORE system CVD risk estimates were used as outcome variables.

Results Following correlation matrix, we entered all variables into principal component analysis (PCA; 76.7\%
\end{abstract}

Electronic supplementary material The online version of this article (doi:10.1007/s40618-016-0601-y) contains supplementary material, which is available to authorized users.

E. Lemche

erwin.lemche@kcl.ac.uk

A. V. Lemche

alexandra.lemche@ikf-berlin.de

O. S. Chaban

chol@i.ua

1 Institute of Clinical Research, Berlin, Germany

2 Section of Psychosomatic Medicine, Bogomolets National Medical University, Kiev, Ukraine

3 Section of Cognitive Neuropsychiatry, Institute of Psychiatry, Psychology and Neuroscience, King's College London, Box PO 69, De Crespigny Park, London SE5 8AF, UK explained variance), followed by hierarchical regression and structural equation modeling (SEM). The PCA suggested a one-factor solution, where the latent variable showed highest loadings of SCORE risk estimates, triglycerides, depression severity, and pulse pressure. A comprehensive SEM was adjusted with $92.7 \%$ explained variance: overall CVD risk related to depression, pulse pressure, triglycerides, and fasting glucose.

Conclusion The findings in this MetS sample suggest that triglycerides and depression severity are the key variables among MetS biomarkers in cross-sectionally associating with the fatal and total SCORE risk estimates in MetS.

Keywords Metabolic syndrome - Triglycerides · Biomarkers · Zung Self-Rating Depression Scale . Structural equation modeling · National sample . Cross-sectional design $\cdot$ Cohort studies $\cdot$ SCORE

$\begin{array}{ll}\text { Abbreviations } \\ \text { MetS } & \text { Metabolic syndrome } \\ \text { T2DM } & \text { Type 2 diabetes mellitus } \\ \text { BMI } & \text { Body mass index } \\ \text { CVD } & \text { Cardiovascular diseases } \\ \text { CHD } & \text { Coronary heart disease } \\ \text { SEM } & \text { Structural equation model } \\ \text { PCA } & \text { Principal component analysis } \\ \text { HPA } & \text { Hypothalamic pituitary adrenocortical axis } \\ \text { ICD } & \text { International Classification of Diseases } \\ \text { IDF } & \text { International Diabetes Federation } \\ \text { SBP } & \text { Systolic blood pressure } \\ \text { DBP } & \text { Diastolic blood pressure } \\ \Delta \text { BP } & \text { Difference blood pressure, pulse pressure } \\ \text { GLM } & \text { General linear model } \\ \text { HRA } & \text { Hierarchical regression analysis } \\ \text { MVLR } & \text { Multi-variable logistic regression }\end{array}$


ANOVA Analysis of variance

TG Triglycerides

HDL High-density lipoprotein

LDL Low-density lipoprotein

VLDL Very low-density lipoprotein

MA Microalbuminuria

TCH Total serum cholesterol

OLS Ordinary least squares

ZSDS Zung Self-Rating Depression Scale

OR Odds ratio

HR Hazard ratio

BDI Beck Depression Inventory

CRP C-reactive protein

\section{Introduction}

There is accumulating evidence for a reciprocal relation between depression and elevated triglycerides (TG) level $[1,2]$, in general, and specifically in the context of the metabolic syndrome (MetS). Serum TG involvement in MetS is herein a key factor, with (a) free fatty acids promoting insulin post-receptor signaling conducive to insulin resistance, (b) hepatic overproduction of very low-density lipoprotein (VLDL, please refer to list of abbreviations for acronyms) and chylomicron residuals, and (c) formation of small-dense LDL and HDL particles with high atherogenic potential from hepatic triglycerides [3, 4]. MetS is a multicomponent condition where endocrinologic, nutritional, and circulation factors, dependent on genomic-environmental interaction and epigenetic programming, enter with increasing age into a mutually degrading spiral, resulting in insulin resistance, cardiovascular adverse events, and ultimately also in neurodegeneration.

Stress-related hypothalamic-pituitary adrenocortical (HPA) axis over-excitability in MetS contributing to cortisol action on metabolic factors has been documented independently by several research groups [5, 6]. Accordingly, available meta-analyses indicate a notion of bi-directionality [7] between depression and MetS, with longitudinal research providing both support for baseline-depression bearing risk for MetS [1, 8], and support for baseline-MetS bearing risk for depression $[2,9,10]$. Whether plasma lipid traits confer risk to cardiovascular events at all is not uncontroversial, yet have influential prospective cohort studies suggested a role of triglycerides in ischemic cardiovascular diseases (CVD) [11, 12].

Genomic and epigenetic studies also point to interactions among those respective genomic bases, which are in greater probability for expression and translation in the presence of adverse contexts in lifestyle, environmental, and personality circumstances [13]. These are, according to current results, then more likely to form epigenetic templates for factors critical to formation of MetS. For example, there is a robust relation between recurrent depression and obesity [14], with the consequence of dyslipidemia, type 2 diabetes mellitus (T2DM), and CVD. For example, subsequent genomic investigations [15] substantiated an epigenetic alteration of FTO gene (16q12.2) polymorphisms, which regulate fat mass and obesity, in the context of depression recurrence. There is also a substantiated epigenetic feedback loop from adiposity to APOA5 and expression of other genes in locus 11q23 then influencing levels of plasma lipid traits TG, HDL, and LDL [16].

In the present study, we investigated within an observational national Ukrainian MetS cohort the cross-sectional relations of MetS biomarkers with self-reported depression levels and CVD risk probabilities as assessed with the SCORE system of the European Cardiological Society. To estimate respective variance proportions and causal interrelation, structural equation modeling (SEM) was employed. Regarding hypotheses, we generally followed the largely replicated observation that depression is a risk factor attenuating survival following cardiovascular events. As a specific hypothesis, we envisaged a role of serum triglycerides in combination with MetS components and depression toward estimation of cardiovascular risk.

\section{Materials and methods}

\section{Participants}

Volunteering participants were recruited from a national pool of MetS patients monitored and treated at specialized units at Railway Hospital No. 2 in Kiev following referral within the countrywide healthcare system of the Ukrainian Ministry of Transport from all parts of Ukraine. Based on endocrinologic parameters or family histories (e.g., parents or siblings affected) indicating specific elevated risk for T2DM, these patients were annually re-examined and treated. Compilation of the final sample $N=101$ (mean age $45.6 \pm 0.14$ SEM years; education levels $4.73 \pm 0.11$, $4=$ junior college level, 67 females) is summarized by the flowchart in Fig. 1 illustrating steps with inclusion and exclusion criteria.

\section{Sample compilation}

Composition and size of the final sample was adapted conforming to designs (e.g., [17]) in biomarker detection studies in MetS, specifically in counterbalancing diabetic and non-diabetic patients. The Institutional Review Board of the National Medical University of the Ukraine had endorsed all procedures. All subjects gave written informed consent to the scientific use of their data and were 
Fig. 1 Flowchart for patient sampling and exclusion steps. Note The final sample in statistical analyses was $N=101$

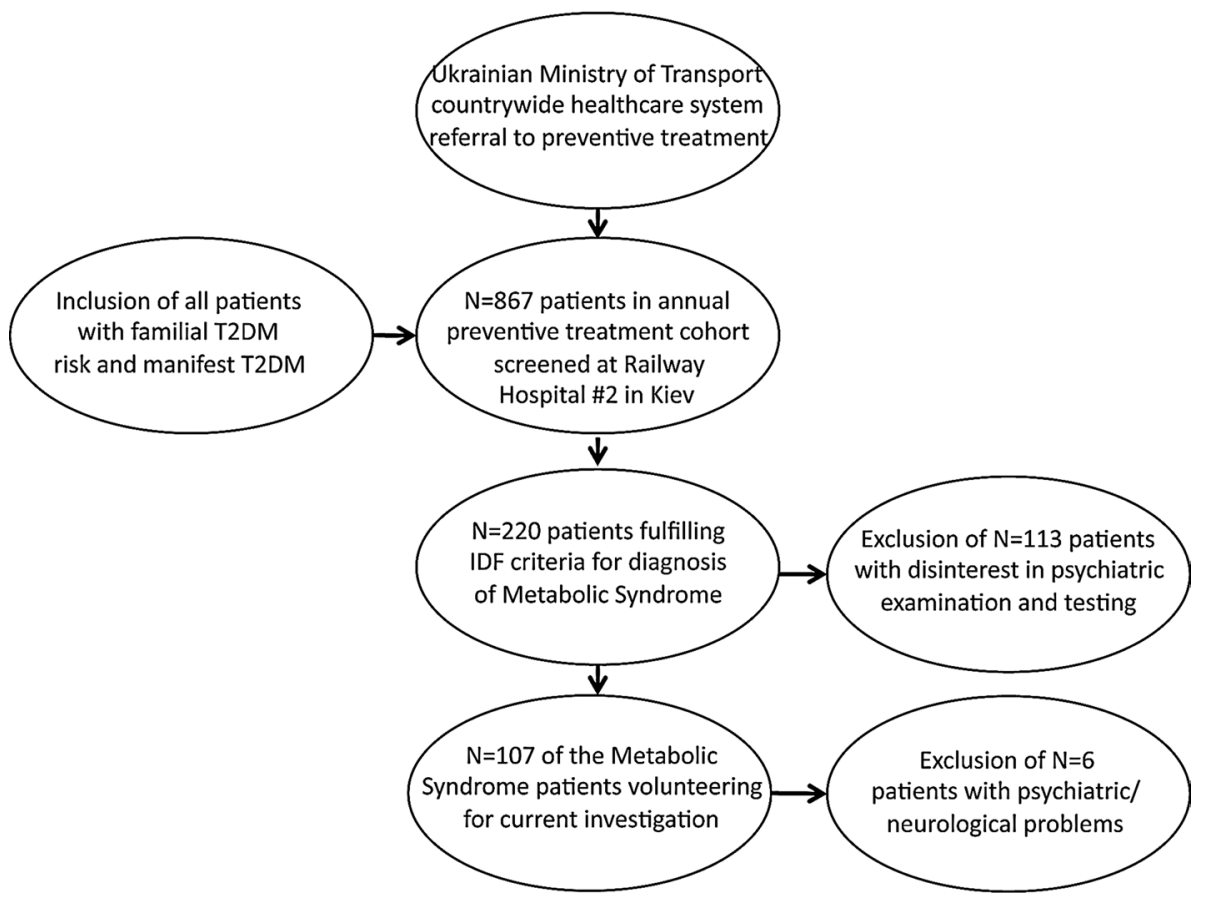

clinical scales were administered for control purposes as previously reported [19, 20]. We focus in this report on results specifically pertaining to depression levels.

\section{Biological laboratory data}

Sitting arterial blood pressure was determined brachially by digital oscillometric sphygmomanometer device upon hospital admission conforming to clinical standard procedures. Pulse pressure was computed as the difference span between SBP and DBP $(\triangle \mathrm{BP})$. Waist circumference was determined by band measure $1 \mathrm{~cm}$ above umbilicus level. Laboratory analyses of all biological specimens were performed in-house with enzymatic methods using commercially available reagents. The laboratory of Railway Hospital No. 2 was subject to quality control standards (e.g., round robin tests) imposed by the Ukrainian Ministry of Public Health and was certified accordingly.

\section{Establishment of cardiovascular risk variables}

Cardiovascular risk estimation was performed based on 2011-2012 criteria of the European Cardiological Society (http://www.escardio.org/guidelines) [21]. The variables individual CVD risk, SCORE fatal risk, and SCORE total risk were established following the instructions. The SCORE system was used with Ukraine classified as a CVD high-risk country. Likewise, following instructions, the variable individual CVD risk was computed by statistical aggregation of seven components. Risk levels for total cholesterol, HDL, LDL, VLDL, Friedewald fraction, 50-59 moderately, and $>60$ severely depressed. Other 
triglycerides, etc., were based on 2002 National Institute of Health (NCEP III) criteria and 2013 American College of Cardiology/American Heart Association cholesterol guidelines [22-24] (S1 Supporting Text for more details).

\section{Statistical methods and models}

Using the recommended standard textbook approach [25], we examined the data in the steps correlation, PCA, HRA, and SEM. The SEM module in STATA, which is based on the Bentler-Weeks regression approach [26, 27] to decomposing variance-covariance matrices, employs the maximum likelihood statistics in fitting observed information matrices (OIM) with the Newton-Raphson stepping algorithm. Our overall SEM approach was the specification of a measurement-based causal model, with using the latent construct indicated by the one-factor solution for overall CVD risk in the preceding PCAs. Error terms were included to estimate measurement error for both observed and latent variables. Following detection of skewness in all three outcome risk variables, these were treated for GLM analyses by log-10 transformation in SPSS (see S1 Supporting Text and S5\&6 Supporting Tables $2 \& 3$ ).

STATA $^{\circledR} /$ MP 12.1 (64-bit version; StataCorp LP, College Station, TX, USA) was used for the statistical methods hierarchical regression analysis (HRA), multivariable logistic regression (MVLR), and structural equation modeling (SEM). IBM SPSS 20 for Intel Macintosh computers (IBM Corp, Armonk, NY, USA) was used to compute correlations, analyses of variance (ANOVA), and principal components analysis (PCA).

\section{Results}

\section{Scale reliability and confounds of the depression measure}

The internal consistency for the ZSDS, as ascertained by Cronbach's coefficient $\alpha=0.824$, was satisfactory for further analyses and well in line with previously reported psychometric properties for this instrument. Examination for confounds of ZSDS revealed that family size (i.e., number of persons actually cohabitating, but not the number of children) was significantly associated with greater depression $(r=0.252)$. Females $(M=46.36 \pm 1.028$ SEM) had significantly severer depression $(t=-2.738$, df $80.42, p=0.008,95 \%$ CI $7.323-1.158$ ) than males $(M=42.12 \pm 1.159$ SEM $)$. Significant relations with depression severity were also found for height $(r=0.201)$ and waist girth $(r=0.347)$. All other sociodemographic and anthropometric measurements were unrelated $(r s<0.2)$ to depression severity. The range of ZSDS distribution depression severity of this sample (S6 Supporting Figure 2) with a prevalence of ZSDS scores $>35$ but remaining $<60$ indicates that the majority in this sample suffers from depression in a mild to moderate strength. Higher depression ranges are missing in this sample in accordance with exclusion criteria (such higher ranges would have indicated severe psychopathology).

\section{Examination of laboratory and risk variables}

Descriptives of all basic study variables are listed (S4 Supporting Table 1). Significant direct associations for biological variables were observed for SBP $(r=0.199)$, pulse pressure $(r=0.239)$, blood pressure risk $(r=0.269)$, trend toward significance were present for Friedewald fraction $(r=0.143)$ and serum triglycerides $(r=0.143)$. Testing for correlation with all other risk variables including microalbuminuria, fasting glucose, total cholesterol, HDL, LDL, and VLDL was insignificant. Of outcome risk variables, zero-order correlations were significant for the latent variable CVD risk $(r=0.223)$, and for computed individual CVD risk. All other risk variables remained insignificant in association with ZSDS, but exhibited strong inter-correlations ( $r$ s 0.634-0.967, all $p \mathrm{~s}<0.0001)$. Sociodemographic confounds for biological variables were rare: Family size was a confounder with Friedewald $(r=0.215)$, blood pressure risk $(r=0.248)$, and triglycerides $(r=0.217)$; education level with triglycerides risk $(r=-0.217)$; number of children with HDL $(r=-0.216)$. Systematic confounds were present for all outcome risk variables individual CVD risk, fatal SCORE, total SCORE, and latent variable CVD risk, with age $(r \mathrm{~s}$ $0.608-0.809$, all $p \mathrm{~s}<0.0001)$, family size ( $r$ s $0.193-0.350$, all $p \mathrm{~s}<0.05)$, and number of children $(r \mathrm{~s} 0.213-0.263$, all $p$ s $<0.05$ ). All other correlations were insignificant. Group differences with respect to clinically depressed status (S6 Supporting Table 3) and diabetic status (S5 Supporting Table 2) revealed that outcome variables exhibit sensitivity toward the respective clinical status.

\section{Preparatory analyses}

PCA, ANOVA, HRA, and MVLR models were tested in preparation of SEMs, as suggested by standard approaches. The results of these analyses are reported in the S1 Supporting Text file linked to this article. The profile plots of the ANOVAs for sex differences in disease severity of MetS are depicted in S2 Supporting Figure 1. In the resulting one-factor solution was the main latent component 1 dominated by combined CVC risk (S7 Supporting Table 4). Testing the factor loadings systematically by HRA and MVLR models corroborated the findings in the PCA (results reported in S1 Supporting Text). 


\section{Structural equation modeling}

The aim of the SEM was the setup and testing of a parsimonious causal model with less than ten paths. Steps in

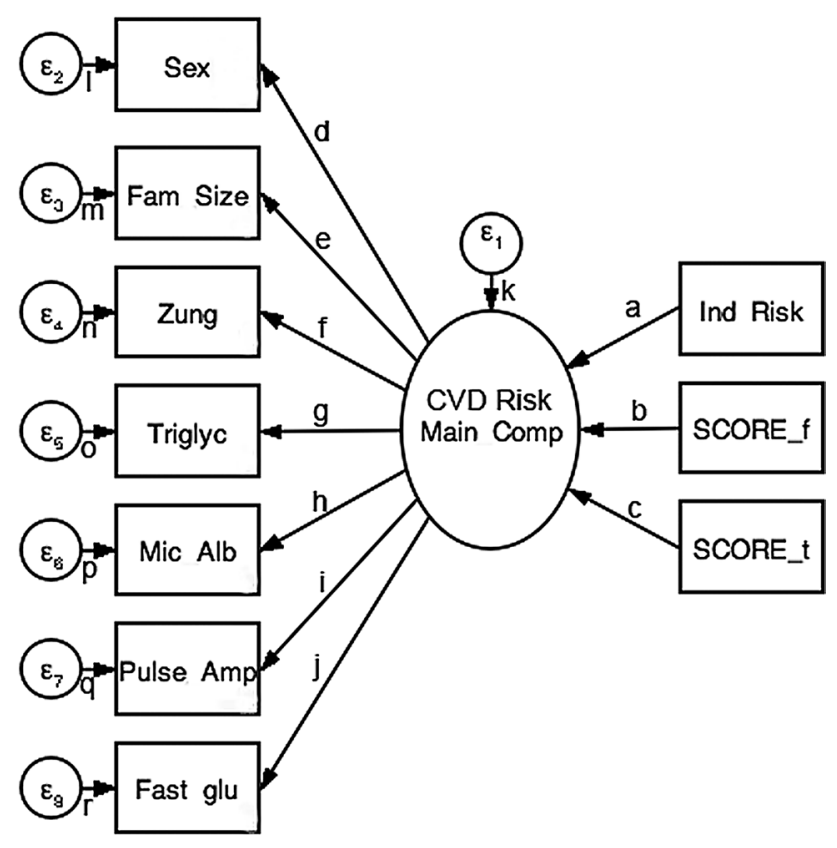

Fig. 2 Diagram of comprehensive SEM. Zung depressivity score, Ind Risk individual CVC risk index, SCORE_t total CVD risk index, $S C O R E \_f$ fatal CVD risk index, $\varepsilon_{1-8}$ error variances, $a-r$ path indicators (see Table 2)
SEM included the setup of measurement-based regression path models, and the inclusion of one latent variable (being both exogenous and endogenous), as suggested by the one-factor solution in PCA (i.e., a one-factor causal model). We tested several part models with both relaxed and constrained errors, inclusion of only single outcome risk variables, and with and without adjustment to sex and comorbidities. Although we could obtain valid and stable models, overall percentage of variance explanation remained in ranges $R^{2}=0.461-0.533$. The best fitting solution was obtained with a model (a) containing sex as an observed variable, (b) including all three outcome CVD risk variables, (c) including adjustment to comorbidities. This final comprehensive SEM is depicted in Fig. 2, with Table 1 reporting path coefficients and their significances, and Table 2 reporting equation-level goodnessof-fit indices. This constrained model with adjustment of standard errors to differential clustering in comorbidities yielded an overall unique variance explanation of $92.7 \%$ in robust OLS path estimation. The adjusted model was distinctly superior to all other solutions (additional information S1 Supporting Text). Please note that none of the traditional SEM goodness-of-fit criteria are reported by STATA in robust estimation. In conclusion, we can state that, out of our computations, the extended and adjusted model yielded best fit, as indicated by the Bentler-Raykov squared multiple correlation coefficients, and the magnitudes in the prediction-correlations (Table 2).

Table 1 Comprehensive structural equation model: path estimation

\begin{tabular}{|c|c|c|c|c|c|c|c|}
\hline Code & Path & Coefficient & Standard error & $Z$ & $P$ & $95 \%$ CI lower & $95 \%$ CI upper \\
\hline $\mathrm{a}$ & Individual risk $\rightarrow$ main component & 0.141 & 0.0154565 & 9.17 & 0.000 & 0.111 & 0.171 \\
\hline $\mathrm{b}$ & SCORE fatal $\rightarrow$ main component & -2.945 & 0.2305982 & -12.77 & 0.000 & -3.397 & -2.493 \\
\hline $\mathrm{c}$ & SCORE total $\rightarrow$ main component & 3.287 & 0.1515965 & 21.69 & 0.000 & 2.990 & 3.584 \\
\hline d & Main component $\rightarrow$ subject sex & 0.453 & 0.0479932 & 9.45 & 0.000 & 0.359 & 0.547 \\
\hline $\mathrm{e}$ & Main component $\rightarrow$ family size & 0.309 & 0.0408251 & 7.59 & 0.000 & 0.229 & 0.389 \\
\hline f & Main component $\rightarrow$ Zung depression score & 0.540 & 0.0312704 & 17.28 & 0.000 & 0.479 & 0.601 \\
\hline g & Main component $\rightarrow$ triglycerides & 0.427 & 0.0326967 & 13.09 & 0.000 & 0.363 & 0.492 \\
\hline $\mathrm{h}$ & Main component $\rightarrow$ microalbuminuria & 0.071 & 0.0097205 & 7.29 & 0.000 & 0.052 & 0.089 \\
\hline $\mathrm{i}$ & Main component $\rightarrow$ pulse pressure & 0.551 & 0.0617042 & 8.94 & 0.000 & 0.431 & 0.672 \\
\hline $\mathrm{j}$ & Main component $\rightarrow$ fasting plasma glucose & 0.364 & 0.0305370 & 11.92 & 0.000 & 0.304 & 0.423 \\
\hline $\mathrm{k}$ & $\varepsilon_{1}$ error main component & 0.073 & 0.0630226 & - & - & 0.013 & 0.395 \\
\hline 1 & $\varepsilon_{2}$ error subject sex & 0.794 & 0.0435319 & - & - & 0.713 & 0.884 \\
\hline $\mathrm{m}$ & $\varepsilon_{3}$ error family size & 0.904 & 0.0252976 & - & - & 0.885 & 0.954 \\
\hline $\mathrm{n}$ & $\varepsilon_{4}$ error Zung depression score & 0.707 & 0.0338024 & - & - & 0.644 & 0.777 \\
\hline o & $\varepsilon_{5}$ error triglycerides & 0.816 & 0.0279834 & - & - & 0.763 & 0.873 \\
\hline $\mathrm{p}$ & $\varepsilon_{6}$ error microalbuminuria & 0.994 & 0.0680616 & - & - & 0.992 & 0.997 \\
\hline q & $\varepsilon_{7}$ error pulse pressure & 0.695 & 0.0222248 & - & - & 0.825 & 0.912 \\
\hline $\mathrm{r}$ & $\varepsilon_{8}$ error fasting plasma glucose & 0.073 & 0.0630216 & - & - & 0.013 & 0.395 \\
\hline
\end{tabular}

a Maximum likelihood estimation, 12 iterations; log pseudolikelihood -364.2662 
Table 2 Equation-level goodness-of-fit indices

\begin{tabular}{lrrrrrrrrl}
\hline Dependents & \multicolumn{1}{c}{ Fitted } & Predicted & Residual & $R^{2}$ & $\mathrm{mc}$ & $\mathrm{mc}^{2}$ & Wald- $\chi^{2}$ & $d f$ & $P$ \\
\hline Subject sex & 0.181 & 0.372 & 0.143 & 0.206 & 0.453 & 0.205 & - & - & - \\
Family size & 1.342 & 0.129 & 1.213 & 0.095 & 0.309 & 0.095 & 424.09 & 1 & 0.0000 \\
Zung depression score & 86.991 & 25.412 & 61.578 & 0.293 & 0.540 & 0.292 & 769.79 & 1 & 0.0000 \\
Triglycerides & 0.675 & 0.123 & 0.551 & 0.183 & 0.428 & 0.183 & 1130.25 & 1 & 0.0000 \\
Microalbuminuria & 0.195 & 0.001 & 0.195 & 0.005 & 0.071 & 0.005 & 84.85 & 1 & 0.0000 \\
Pulse pressure & 132.074 & 40.188 & 91.936 & 0.304 & 0.551 & 0.304 & 511.55 & 1 & 0.0000 \\
Fasting plasma glucose & 4.053 & 0.536 & 3.516 & 0.132 & 0.363 & 0.132 & 1937.60 & 1 & 0.0000 \\
Main component & 0.037 & 0.034 & 0.003 & 0.926 & 0.962 & 0.926 & 1074.60 & 3 & 0.0000 \\
Overall & & & & 0.927 & & & & & \\
\hline
\end{tabular}

$m c$ correlation between the dependent variable and its prediction, $m c^{2}$ the Bentler-Raykov squared multiple correlation coefficient. Stability analysis yields a stability index $=0$ : SEM satisfies stability condition

$P$ value tested against random permutation

\section{Discussion}

The main findings of this study are that, as SEM suggests, overall CVD risk in MetS is associated with an ensemble of single biomarkers (triglycerides, microalbuminuria, fasting glucose level, pulse pressure), single sociodemographic markers and mid-range depression. The results of this study specifically highlight the role of triglycerides in dyslipidemia associated with self-reported depression level as contributing to overall CVD risk in MetS with $29.3 \%$ explained variance accounted for. With respect to hypothesis testing, the results in this MetS sample provide further support for manifold findings that depression level is predictive for CVD-related mortality (here indicated by SCORE fatal estimates). In this sample, the pattern of cross-sectional association is such that triglycerides rather than the other lipid traits (cholesterol fractions) exerted the major risk contributing $18.3 \%$ to overall CVD risk of 92.7\%. As triglycerides are still seen as an "emerging risk factor" (NCEP III guidelines of 2002, ESC guidelines of 2012), this finding provides relative novelty to respective accumulating evidence.

Regarding the relation of depression and mortality, there are consistencies with published literature in this respect. There is an increased risk for mortality (OR 1.5) [28] according to the recent meta-analyses, where CVD is among the main causes of mortality associated with depression. Also, for a relation of depression symptoms and dyslipidemia there is replicated support. A recent Finnish longitudinal developmental study spanning preschool measurement with adulthood indicated that trajectories of steep increases in triglycerides were predictive of depression onset [29]. One prospective study in congenital heart disease for major adverse cardiovascular events (fatal and hospitalization incidences) related to depression indicated ORs 1.6-3.6 for a 5-year period [30]. The cross-sectional fatal SCORE risk in a Finnish regional study for depression was OR 2.9 for males and OR 1.3 for females with $30 \%$ of MetS prevalence [31]. In myocardial infarction survivors increases depression onset the longitudinal risk for subsequent cardiovascular adverse events at a HR 1.7, with proportional higher risk for more depressed patients [32]. Also, for stroke, moderate depression assessed with ZSDS resulted in independent risks (ORs 1.9-2.7) [33]. Likewise, in a Dutch 10-year longitudinal study, BDI depression scores rather than actual clinical depression, proved as a better independent predictor, with HR 3.9 for cardiac mortality and 1.7 for non-fatal cardiac events [34].

Also in healthy individuals is depression (ZSDS) associated with inflammation marker C-reactive protein (CRP), leukocytes, and fibrinogen, as a regional Greek study found [35]. In stable CHD patients proved ZSDS a better predictor at OR 1.1 of later adverse cardiovascular events than CRP baseline levels, also in a Greek two-step study [36]. In all studies, depression is found an independent predictor of CVD risk, but MetS components such as diabetes or abdominal obesity also form significant interactions [37]. Psychosocial stress and depression (ZSDS) have associations with different biomarkers, but triglycerides may be a linking variable: in an Italian study, depression correlated with triglycerides, which were also associated with stress scores [38].

The best supported explanatory mechanism for the elevated CHD risk in depression is a dysregulated HPA axis, involving sympathetic overstimulation and hypercortisolemia [39]. HPA dysfunction and MetS criteria were more prevalent in the melancholic subtype of clinical depression [40]. Reduction in telomere length as a result of stress is associated both to single MetS components, including triglycerides, and also progression into MetS constellation [41]. In structural neuroimaging, volume reduction in the nucleus globus pallidus correlated both with MetS severity and depression severity, thus providing a putative brain correlate of MetS [42] (S1 Supporting Text). 
One strength of this study lies in countrywide sampling and the high level overall explained variance in SEM. The current study is limited due to its sample size and crosssectional design, albeit provides robust statistical effects. Further limitations lie in the non-inclusion of direct neuroendocrine measurement and lack of genotype control.

\section{Conclusion}

This study presents evidence in support of the hypothesis that levels of triglycerides play a major role in overall CVD risk in MetS. Manifold evidence has long described depression, CVD-related mortality in the context of MetS symptoms as long-term consequences of dysregulated HPA. The present findings add to these postulates by estimating risks and showing patterns of association cross-sectionally. Future studies should use prospective design and be controlling for genotype and indices of signaling in neuroendocrine pathways in question.

Acknowledgements A.V.L. acknowledges intramural funding from the National Medical University of the Ukraine, Kiev. O.S.C. was supported by a center grant on "Quality of Life in Diabetes" from the Ministry of Public Health of the Ukraine. The funders had no role whatsoever in design, analyses, or manuscript preparation.

Author contribution AVL designed the study, performed the statistical analyses, interpreted the results, and drafted the manuscript. OSC designed the study protocol. EL inspected the raw data, supervised data management, and performed the advanced statistical procedures. All authors contributed to, revised, and approved the final manuscript.

\section{Compliance with ethical standards}

Conflict of interest The authors have no conflicts of interest to disclose.

Ethical approval This study was approved by the Institutional Review Board of the National Medical University of the Ukraine.

Informed consent Our research involved human participants who had obtained informed consent.

Open Access This article is distributed under the terms of the Creative Commons Attribution 4.0 International License (http://creativecommons.org/licenses/by/4.0/), which permits unrestricted use, distribution, and reproduction in any medium, provided you give appropriate credit to the original author(s) and the source, provide a link to the Creative Commons license, and indicate if changes were made.

\section{References}

1. Toker S, Shirom A, Melamed S (2008) Depression and the metabolic syndrome. Depress Anxiety 25(8):661-669
2. Igna CV, Julkunen J, Vanhanen H (2011) Vital exhaustion, depressive symptoms and serum triglyceride levels. Psychiatry Res 187(3):363-369

3. Blaton VH, Korita I, Bulo A (2008) How is metabolic syndrome related to dyslipidemia? Biochem Med 18(2):14-24

4. Pang J, Chan DC, Watts GF (2014) Origin and therapy for hypertriglyceridaemia in type 2 diabetes. World J Diabetes 5(2):165-175

5. Brunner EJ, Hemingway $H$, Walker BR, Page M, Clarke $P$, Juneja M, Shipley MJ, Kumari M, Andrew R, Seckl JR et al (2002) Adrenocortical, autonomic, and inflammatory causes of the metabolic syndrome. Circulation 106(21):2659-2665

6. Kuehl LK, Hinkelmann K, Muhtz C, Dettenborn L, Wingenfeld K, Spitzer C, Kirschbaum C, Wiedemann K, Otte C (2015) Hair cortisol and cortisol awakening response are associated with criteria of the metabolic syndrome. Psychoneuroendocrinology 51:365-370

7. Pan A, Keum N, Okereke OI, Sun Q, Kivimaki M, Rubin RR, Hu FB (2012) Bidirectional association between depression and metabolic syndrome. Diabetes Care 35(5):1171-1180

8. Pan A, Sun Q, Czernichow S, Kivimaki M, Okereke OI, Lucas M, Manson JE, Ascherio A, Hu FB (2012) Bidirectional association between depression and obesity. Int $\mathrm{J}$ Obes (Lond) 36(4):595-602

9. Akbaraly TN, Kivimaki M, Brunner EJ, Chandola T, Marmot MG, Singh-Manoux A, Ferrie JE (2009) Association between metabolic syndrome and depressive symptoms. Diabetes Care 32(3):499-504

10. Almeida OP, Calver J, Jamrozik K, Hankey GJ, Flicker L (2009) Obesity and metabolic syndrome increase the risk of incident depression. Am J Geriatr Psychiatry 17(10):889-898

11. Jorgensen AB, Frikke-Schmidt R, Nordestgaard BG, TybjaergHansen A (2014) Loss-of-function mutations in APOC3 and risk of ischemic vascular disease. N Engl J Med 371(1):32-41

12. Freiberg JJ, Tybjaerg-Hansen A, Jensen JS, Nordestgaard BG (2008) Nonfasting triglycerides and risk of ischemic stroke in the general population. JAMA 300(18):2142-2152

13. Lemche E, Chaban OS, Lemche AV (2016) Neuroendocrine and epigenetic mechanisms subserving autonomic imbalance and HPA dysfunction in the metabolic syndrome. Front Neurosci 10(4): 142

14. Farmer A, Korszun A, Owen MJ, Craddock N, Jones L, Jones I, Gray J, Williamson RJ, McGuffin P (2008) Medical disorders in people with recurrent depression. Br J Psychiatry 192(5):351-355

15. Rivera M, Cohen-Woods S, Kapur K, Breen G, Ng MY, Butler AW, Craddock N, Gill M, Korszun A, Maier W et al (2012) Depressive disorder moderates the effect of the FTO gene on body mass index. Mol Psychiatry 17(6):604-611

16. Cole CB, Nikpay M, Lau P, Stewart AF, Davies RW, Wells GA, Dent R, McPherson R (2014) Adiposity significantly modifies genetic risk for dyslipidemia. J Lipid Res 55(11):2416-2422

17. Huang CF, Cheng ML, Fan CM, Hong CY, Shiao MS (2013) Nicotinuric acid: a potential marker of metabolic syndrome through a metabolomics-based approach. Diabetes Care 36(6):1729-1731

18. Zung WW (1965) A self-rating depression scale. Arch Gen Psychiatry $12: 63-70$

19. Lemche AV, Chaban OS, Lemche E (2013) Alexithymia as a risk factor for type 2 diabetes mellitus in the metabolic syndrome. Psychiatry Res 215(2):438-443

20. Lemche AV, Chaban OS, Lemche E (2013) Aggressivity and hostility traits affect different cardiovascular risk profiles in the metabolic syndrome. Int J Cardiol 171(3):e76-e77

21. Reiner Z, Catapano AL, De Backer G, Graham I, Taskinen MR, Wiklund O, Agewall S, Alegria E, Chapman MJ, Durrington P 
et al (2011) ESC/EAS Guidelines for the management of dyslipidaemias. Eur Heart J 32(14):1769-1818

22. Stone NJ, Robinson JG, Lichtenstein AH, Bairey Merz CN, Blum CB, Eckel RH, Goldberg AC, Gordon D, Levy D, LloydJones DM et al (2013) ACC/AHA guideline on the treatment of blood cholesterol to reduce atherosclerotic cardiovascular risk. J Am Coll Cardiol 63(25 Pt B):2889-2934

23. Stone NJ, Robinson JG, Lichtenstein AH, Bairey Merz CN, Blum CB, Eckel RH, Goldberg AC, Gordon D, Levy D, LloydJones DM et al (2014) 2013 ACC/AHA guideline on the treatment of blood cholesterol to reduce atherosclerotic cardiovascular risk. Circulation 129(25 Suppl 2):S1-S45

24. Stone NJ, Robinson JG, Lichtenstein AH, Goff DC Jr, LloydJones DM, Smith SC Jr, Blum C, Schwartz JS (2014) Treatment of blood cholesterol to reduce atherosclerotic cardiovascular disease risk. Ann Intern Med 160(5):339-343

25. Weiber R, Mühlhaus D (2010) Strukturgleichungsmodellierung. Springer, Heidelberg

26. Bentler PM, Weeks DG (1990) Linear structural equations with latent variables. Psychometrika 45:289-308

27. Bentler PM, Weeks DG (1979) Interrelations among models for the analysis of moment structures. Multivar Behav Res 14:169-185

28. Cuijpers P, Vogelzangs N, Twisk J, Kleiboer A, Li J, Penninx BW (2014) Comprehensive meta-analysis of excess mortality in depression in the general community versus patients with specific illnesses. Am J Psychiatry 171(4):453-462

29. Elovainio M, Pulkki-Raback L, Kivimaki M, Jokela M, Viikari J, Raitakari OT, Telama R, Keltikangas-Jarvinen L (2010) Lipid trajectories as predictors of depressive symptoms. Health Psychol 29(3):237-245

30. Kourkoveli P, Rammos S, Parissis J, Maillis A, Kremastinos D, Paraskevaidis I (2014) Depressive symptoms in patients with congenital heart disease. Congenit Heart Dis 10(3):240-247. doi: $10.1111 /$ chd. 12200

31. Koponen H, Jokelainen J, Keinanen-Kiukaanniemi S, Vanhala M (2010) Depressive symptoms and 10-year risk for cardiovascular morbidity. World J Biol Psychiatry 11(6):834-839

32. Shiozaki M, Iso H, Ohira T, Nakatani D, Shimizu M, Sakata Y, Komuro I, Sato H (2011) Longitudinal risk of cardiovascular events in relation to depression symptoms after discharge among survivors of myocardial infarction. Circ J 75(12):2878-2884

33. Ohira T, Iso H, Satoh S, Sankai T, Tanigawa T, Ogawa Y, Imano H, Sato S, Kitamura A, Shimamoto T (2001) Prospective study of depressive symptoms and risk of stroke among Japanese. Stroke 32(4):903-908

34. Zuidersma M, Conradi HJ, van Melle JP, Ormel J, de Jonge P (2013) Self-reported depressive symptoms, diagnosed clinical depression and cardiac morbidity and mortality after myocardial infarction. Int J Cardiol 167(6):2775-2780

35. Panagiotakos DB, Pitsavos C, Chrysohoou C, Tsetsekou E, Papageorgiou C, Christodoulou G, Stefanadis C (2004) Inflammation, coagulation, and depressive symptomatology in cardiovascular disease-free people. Eur Heart J 25(6):492-499

36. Rallidis LS, Varounis C, Sourides V, Charalampopoulos A, Kotakos C, Liakos G, Dagres N, Apostolou T, Anastasiou-Nana M (2011) Mild depression versus C-reactive protein as a predictor of cardiovascular death. Curr Med Res Opin 27(7):1407-1413

37. Rutledge T, Linke SE, Johnson BD, Bittner V, Krantz DS, Cornell CE, Vaccarino V, Pepine CJ, Handberg EM, Eteiba W et al (2012) Relationships between cardiovascular disease risk factors and depressive symptoms as predictors of cardiovascular disease. J Womens Health (Larchmt) 21(2):133-139

38. Bove M, Carnevali L, Cicero AF, Grandi E, Gaddoni M, Noera G, Gaddi AV (2010) Psychosocial factors and metabolic parameters. Aging Ment Health 14(7):801-806

39. Goldston K, Baillie AJ (2008) Depression and coronary heart disease. Clin Psychol Rev 28(2):288-306

40. Lamers F, Vogelzangs N, Merikangas KR, de Jonge P, Beekman AT, Penninx BW (2013) Evidence for a differential role of HPAaxis function, inflammation and metabolic syndrome in depression. Mol Psychiatry 18(6):692-699

41. Revesz D, Milaneschi Y, Verhoeven JE, Penninx BW (2014) Telomere length as a marker of cellular ageing is associated with prevalence and progression of metabolic syndrome. J Clin Endocrinol Metab 99(12):4607-4615. doi:10.1210/jc.2014-1851

42. Onyewuenyi IC, Muldoon MF, Christie IC, Erickson KI, Gianaros PJ (2014) Basal ganglia morphology links the metabolic syndrome and depressive symptoms. Physiol Behav 123:214-222 